Hydrophilidae. The author writes with intimate knowledge of the species dealt with, acquired during his long experience as a field naturalist. As in the previous volumes, no descriptions are given of the species, and a successful identification is dependent on the correct interpretation of the keys, aided, however, by many useful figures illustrating anatomical features. An account of the life-history of the Hydrophilidae is included in the introduction, and many interesting biological notes are scattered throughout the book. More information on the larvæ and their habitats-where these are known-would have been of much value, but it is hoped that this book will induce others to study the biology of these interesting beetles, as Prof. Balfour-Browne has done so ably in the case of Hydrobius fuscipes, L.

The maps showing county and vice-county boundaries are a great improvement on those given in the earlier volumes, and are most useful in showing at a glance the known distribution of a species. Few errors have been noticed in the text, but no map is given of Ochthebius minimus Fab. though quoted on p. 160, and many authors are mentioned without inclusion in the bibliography. An interesting account is given of the male genitalia in some species of Ochthebius, Hydroena and Hydrochus. The author considers that the modifications described render the males of some species incapable of mating and he believes that in consequence parthenogenesis occurs. This is a problem requiring investigation.

Highly controversial are the anthor's views given under the heading "Distribution and Means of Transport", though what transport he envisages for flightless water beetles is not specified. His outlook on the problem of the present distribution of water beetles is dominated by his idea of recent "invasions" arriving not only at the coast from the Continent but accounting also for the occurrence of various local species, adapted to special habitats, in all parts of the country, such as Helophorus tuberculatus Gyll, in Lanark (p. 96). The occurrence of uncommon species in localities not previously or recently worked is no proof of their recent arrival, and especially is this true when the specimens collected are incapable of flight, as in the case cited (p. lii) of Noterus crassicornis Müll., a species which is common in a Fife loch where 90 specimens have been taken, all brachypterous. It is more likely that local aquatic species are the last remnants of a population that was formerly much more extensive, before drainage and cultivation had destroyed many habitats.

Argument is an excellent stimulus to further research, and Prof. Balfour-Browne has written a stimulating book which will arouse fresh interest in these beetles and prove of much value to the specialist.

DOROTHY J. JACKSON

\section{THE ELUSIVE PARTICLE}

\section{The Neutrino}

By Prof. James S. Allen. (Investigations in Physics, No. 5.) Pp. viii + 168. (Princeton, N.J. : Princeton University Press; London: Oxford University Press, 1958.) 36s. net. $7 \begin{aligned} & \text { HIS small book gives an excellent description of } \\ & \text { experimental work on the neutrino, which only }\end{aligned}$ in the past few years has been shown to have any direct physical property apart from balancing energy, momentum and spin in $\beta$-decays. It is a tribute to modern methods of experiment that neutrino- capture in hydrogen has been demonstrated by Reines and Cowan in spite of the fact that a neutrino beam could traverse a thickness of solid material measured in light years without appreciable loss. The timing of the book was unlucky, because it was written before or during the revolution which occurred in the last half of 1957 and in 1958, due to the discovery of the non-conservation of parity in $\beta$-decay. Dr. Allen was therefore obliged to cover the changes in "Notes added in Proof". This he has done satisfactorily, but the subject has been so much changed very recently that a much clearer picture would be possible now.

Nevertheless the book is a useful one since it is concerned mainly with descriptions of experimental methods in the very difficult field of neutrino physics, and does not go into details of theories, some of which have changed.

The subject has had a curious history. Experimentalists were misled for many years by the conservation of parity theory, which was not based on any universally valid evidence, into not looking for such an easily detectable phenomenon as the polariza. tion of electrons in $\beta$-decay. Some wrong results in the electron-neutrino angular correlation experiments, understandable in view of their difficulty, also contributed to the confusion. However, now everything seems in order on the two-component neutrino theory of Lee and Yang, both for $\beta$-decay and for pion decay. It has not happened often that so tricky a field of physics has been cleared up so quickly, as a result of brilliant theoretical work, which suggested many key experiments.

H. W. B. SkinNer

\section{LEGENDRE FUNCTIONS}

\section{Fonctions Sphériques de Legendre et Fonctions Sphéroidales}

Tome 2. Par Dr. Louis Robin. (Collection Technique et Scientifique du C.N.E.T.) Pp. viii +384 . (Paris : Gauthier-Villars, 1958.) 5,300 franes.

THE second volume of Dr. Robin's comprehensive treatise deals with the associated Legendre functions $P^{m} n(\mu), Q^{m} n(\mu)$. The problem of defining these functions for unrestricted complex values of $m, n$ and $\mu$ was tackled by several mathematicians in the late nineteenth century, and finally solved by Hobson (1896), who used for this purpose the doublecircuit contour integrals devised by Jordan and Pochhammer. An essentially complete theory was expounded in full in Hobson's classical treatise on spherical harmonics (1931), and Dr. Robin has based his book very largely on this work, with some extensions and some elaboration of detail. There are three sections. In the first, which occupies more than half the book, the formal discussion of the functions is developed in exhaustive fashion. In the second, asymptotic formulæ and the Stieltjes-Hobson inequalities are considered; in the third, convergence and summability of series of Legendre functions. The influence of Hobson and of other British mathematicians, for example, Barnes, Watson, MacRobert, is very evident, and littlo of importance has escaped the author's attention. The book is for reference rather than for light reading, and for British readers is scarcely likely to replace Hobson; but Dr. Robin has taken account of work done since 1931, and has also incorporated earlier work, for example, on 